\title{
Transrectal real-time tissue elastography targeted biopsy coupled with peak strain index improves the detection of clinically important prostate cancer
}

\author{
QI MA $^{1 *}$, DONG-RONG YANG ${ }^{2 *}$, BO-XIN XUE ${ }^{2}$, CHENG WANG $^{1}$, \\ HAN-BIN CHEN $^{1}$, YUN DONG ${ }^{3}$, CAI-SHAN WANG ${ }^{1}$ and YU-XI SHAN ${ }^{2}$ \\ Departments of ${ }^{1}$ Ultrasound and ${ }^{2}$ Urology, The Second Affiliated Hospital of Soochow University, Suzhou, \\ Jiangsu 215004; ${ }^{3}$ Department of Pathology, Wuxi Affiliated Hospital of Nanjing University of \\ Chinese Medicine, Wuxi, Jiangsu 214071, P.R. China
}

Received September 3, 2015; Accepted January 10, 2017

DOI: $10.3892 / \mathrm{ol} .2017 .6126$

\begin{abstract}
The focus of the present study was to evaluate transrectal real-time tissue elastography (RTE)-targeted two-core biopsy coupled with peak strain index for the detection of prostate cancer ( $\mathrm{PCa}$ ) and to compare this method with 10-core systematic biopsy. A total of 141 patients were enrolled for evaluation. The diagnostic value of peak strain index was assessed using a receiver operating characteristic curve. The cancer detection rates of the two approaches and corresponding positive cores and Gleason score were compared. The cancer detection rate per core in the RTE-targeted biopsy (44\%) was higher compared with that in systematic biopsy (30\%). The peak strain index value of $\mathrm{PCa}$ was higher compared with that of the benign lesion. PCa was detected with the highest sensitivity $(87.5 \%)$ and specificity $(85.5 \%)$ using the threshold value of a peak strain index of $\geq 5.97$ with an area under the curve value of 0.95 . When the Gleason score was $\geq 7$, RTE-targeted biopsy coupled with peak strain index detected $95.6 \%$ of PCa cases, but $84.4 \%$ were detected using systematic biopsy. Peak strain index as a quantitative parameter may improve the differentiation of PCa from benign lesions in the prostate peripheral zone. Transrectal RTE-targeted biopsy coupled with peak strain index may enhance the detection of clinically significant PCa, particularly when combined with systematic biopsy.
\end{abstract}

Correspondence to: Professor Yu-Xi Shan, Department of Urology, The Second Affiliated Hospital of Soochow University, 1055 Sanxiang Road, Suzhou, Jiangsu 215004, P.R. China

E-mail: yuxishancn@163.com

*Contributed equally

Key words: transrectal ultrasound, elastography, strain index, prostate cancer, prostate biopsy

\section{Introduction}

Prostate cancer (PCa) is the second most prevalent cause of cancer-associated mortality globally (1). The incidence and mortality of PCa has continually increased within the past decade in China, but remains low compared with Western countries (2). The incidence of PCa in China is predicted to increase further due to diet and lifestyle changes and the aging population (3). Transrectal systematic biopsy is the standard procedure for the detection of $\mathrm{PCa}$. The procedure is invasive and causes discomfort for patients; however, 18 to $47 \%$ of cases of PCa may not be detected by this method, whereas a number of clinically insignificant alterations to the prostate may be misdiagnosed as PCa following detection by systematic biopsy (4-7). Therefore, novel methods for the effective and safe detection of clinically significant $\mathrm{PCa}$ are required.

PCa tissues may exhibit increased stiffness due to pathological alterations (8). Tissue elasticity has potential as a novel diagnostic factor for PCa (9). Real-time tissue elastography (RTE) is a sonoelastography approach that uses colors to visualize the variations in tissue elasticity or stiffness. In the diagnosis of $\mathrm{PCa}$, the sensitivity and specificity of RTE-targeted biopsy varies from 51.1 to $91.7 \%$ and from 62.2 to $86.8 \%$, respectively (10-14). This is as the majority of previous studies use the qualitative threshold 'blue area' for diagnosis, which results in variability between the inter- and intra-observer. However, RTE has not been quantitatively analyzed in targeted biopsies for the detection of $\mathrm{PCa}$.

Strain index is a quantitative parameter for comparing the strain value of two tissues during histological analysis. Zhang et al (15) used the peak strain index for classifying benign and suspicious malignant lesions in the peripheral zone of the prostate and yielded higher sensitivity (74.5\%) and specificity (83.3\%). However, whether peak strain index may aid the diagnosis of clinically significant PCa has yet to be elucidated.

In the present study, the optimal peak strain index in RTE-targeted biopsies was defined for the detection of $\mathrm{PCa}$ in Chinese patients, and it was identified that RTE-targeted 
biopsy coupled with the peak strain index may improve the detection rate of clinically significant peripheral zone PCa.

\section{Materials and methods}

Patients with PCa. Between February 2011 and September 2013, patients with lower urinary tract symptoms were examined for their serum prostate specific antigen (PSA) prior to undergoing a digital rectal examination (DRE) and a transrectal ultrasound (TRUS) at The Second Affiliated Hospital of Soochow University (Jiangsu, China). Patients presenting with an active urinary tract infection or acute urinary retention were excluded from the present study. The following criteria were used to determine the need for a prostate biopsy: a) APSA value of $\geq 10 \mathrm{ng} / \mathrm{ml}$; b) a PSA value of between 4 and $10 \mathrm{ng} / \mathrm{ml}$, and a free-to-total PSA of $<16 \%$; c) DRE or TRUS indicated a prostate nodule. The present study was approved by the Institutional Ethics Committee of The Second Affiliated Hospital of Soochow University and all patients provided written informed consent prior to being enrolled onto the study.

RTE targeted biopsy. A Hitachi EUB-7500HV ultrasound system with a EUP-V53W 7.5-MHz transrectal end-fire probe (Hitachi, Ltd., Tokyo, Japan) was used in the RTE mode. The patient was in the left decubitus position and elastograms were produced by manual compression from the transverse plane and displayed with TRUS images. The pressure and speed induced by manual compression was adjusted by a visual indicator designed to decrease the inter-observer variability. The strain of tissue was classified as soft, moderate and hard according to the colors displayed, in which red signifies high strain (soft), green indicates moderate strain and blue indicates low strain (hard; Fig. 1). Hard lesions that present as blue areas in elastograms were considered to be potential malignant lesions (16). Stable and reproducible elastograms were recorded for further analysis. Regions with calcifications in the prostate are stiff and may affect the elastogram results. However, they are hyperechoic on the TRUS image and were able to be identified and avoided during the biopsy (Fig. 1).

The quantitative parameter peak strain index was calculated using the following formula: Strain ratio (SR) of the surrounding reference tissue (B) that exhibited moderate elasticity (green area) to SR of the peak elasticity (area with the highest level of blue) region $(A)\left(S_{B} / S_{A}\right)$. The smallest size of the region of interest (ROI) in the RTE mode was determined as the standard. A number of sections in the most intense blue areas were measured to determine the highest outstanding peak elasticity.

Two cores were obtained from the hardest area with an 18-gauge biopsy needle. All examinations and targeted biopsies were performed by a single examiner who was blind to the results of the PSA test and other modalities.

Systematic biopsy. Following the RTE-targeted biopsy, a 10-core systematic biopsy that was independent of the RTE and TRUS findings was performed by a different examiner (The Second Affiliated Hospital of Soochow University). A $\mathrm{MyLab}^{\mathrm{TM}} 90$ ultrasound system with an EC-123 7.5-MHz transrectal end-fire probe (EsaoteSpA, Genova, Italy) was used

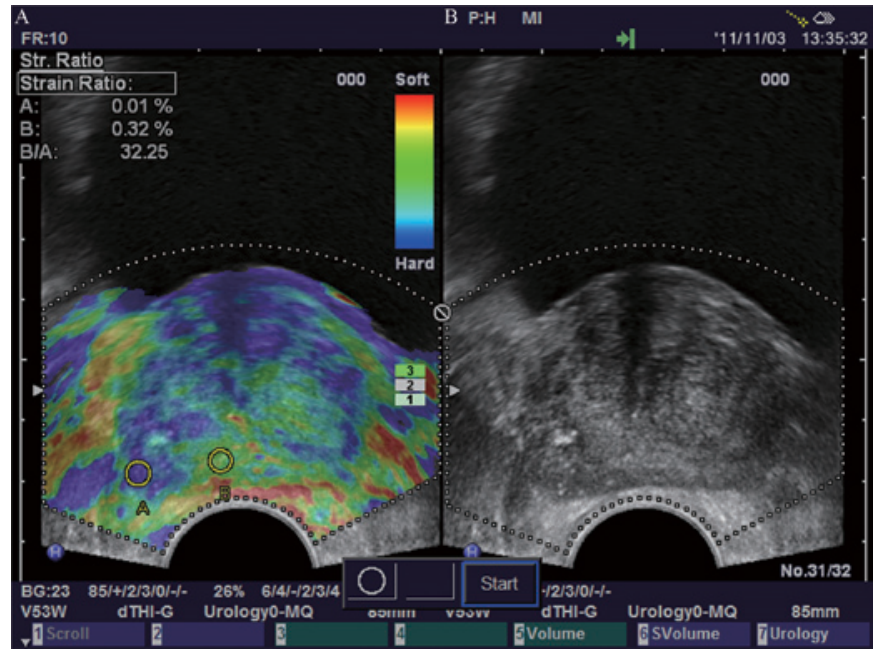

Figure 1. RTE image with the peak strain index. (A) RTE image and (B) TRUS image. The pressure and speed induced by manual compression maybe adjusted using a visual indicator (' 3 ' in the green box). RTE indicates a stiff (blue) area on the right side of the prostate, which may be indicative of prostate cancer. Peak strain index was 32.25 when the local region of peak elasticity (area with the highest level of blue) was selected as $\mathrm{ROI}_{\mathrm{A}}$ and the reference tissue was selected as $\mathrm{ROI}_{\mathrm{B}}$. Calcifications on the right side of the prostate were displayed as hyperechoic and maybe identified on the TRUS image. RTE, real-time tissue elastography; TRUS, transrectal ultrasound; ROI, region of interest.

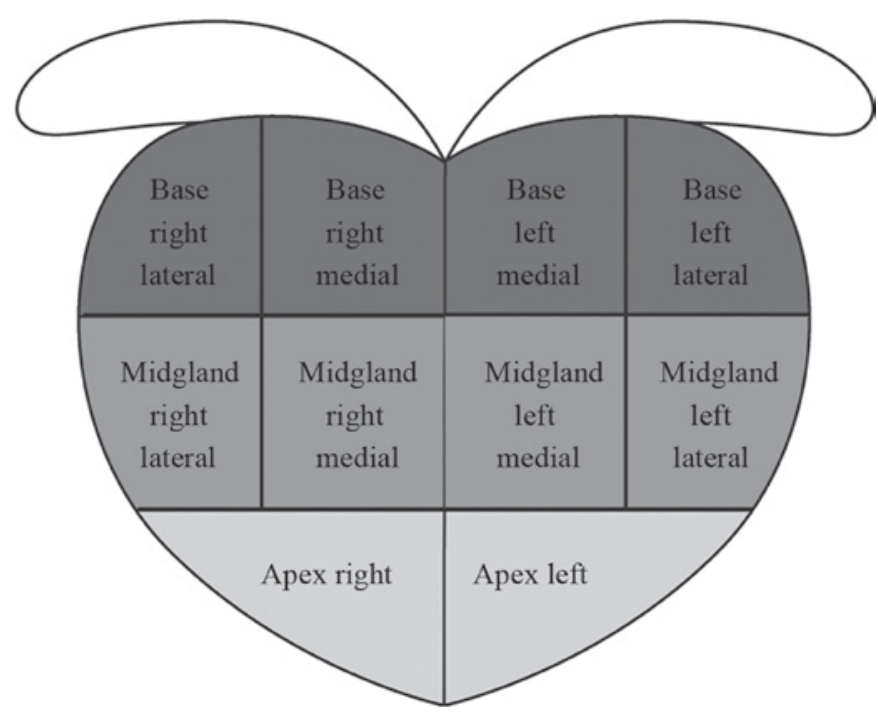

Figure 2. Prostate peripheral zone anatomy. 10 core biopsies were obtained from the base ( 2 cores), midgland ( 2 cores) and apex ( 1 core) from each side of the prostate.

in TRUS mode. The 10 cores included 3 lateral and 2 medial cores in the left and right sides (Fig. 2). All the cores were guided by six dorsal gland sectors: Apex, middle and basement on the left and right sides. The inner gland analysis was not included in the results. The average time of RTE examination and targeted biopsy for each patient was $\sim 10 \mathrm{~min}$.

Pathologic analysis. All cores were marked by identification numbers and analyzed by a senior pathologist (Wuxi Affliated Hospital of Nanjing University of Chinese Medicine) who was blind to the results of the RTE and TRUS. 
Table I. Characteristics of patients with benign or malignant prostate lesions.

\begin{tabular}{|c|c|c|c|c|}
\hline Characteristic & Benign mean (range) & Malignant mean (range) & Overall mean (range) & P-value \\
\hline Number of patients & 69 & 72 & 141 & \\
\hline Age, years & $70.50(55-85)$ & $72.60(49-90)$ & $71.60(49-90)$ & 0.1422 \\
\hline PSA, ng/ml & $10.40(0.5-47.6)$ & $48.80(1.1-190)$ & $30.00(0.5-190)$ & $<0.0001$ \\
\hline Prostate volume, ml & $51.20(24.7-178.5)$ & $49.40(15.8-171)$ & $50.30(15.8-178.5)$ & 0.1996 \\
\hline Peak strain index & $3.02(0.5-26.3)$ & $24.79(1.39-66.9)$ & $14.00(0.5-66.9)$ & $<0.0001$ \\
\hline
\end{tabular}

PSA, prostate specific antigen.

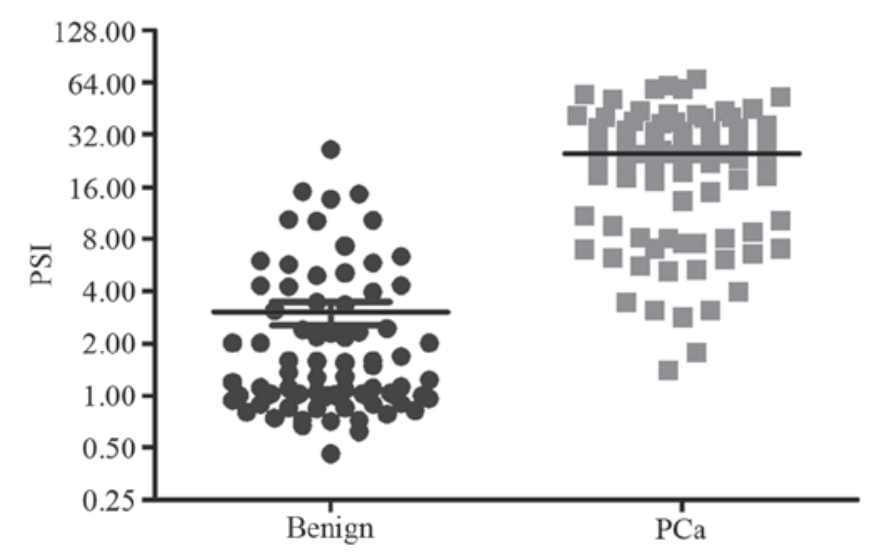

Figure 3. Significant difference between the PSI values in the benign lesions and $\mathrm{PCa}$ lesions $(\mathrm{P}<0.0001)$. Mean value is presented as a black line. PSI, peak strain index; $\mathrm{PCa}$, prostate cancer.

Statistical analysis. Peak strain index comparisons between malignant and benign lesions were analyzed by the student's t-test or Wilcoxon rank sum test. The diagnostic values of peak strain index and PSA were assessed by receiver operating characteristic (ROC) curves. Areas under the ROC curve (AUC) values between the peak strain index and PSA were compared using a $\chi^{2}$ test. To evaluate the significance of the differences between targeted biopsy and systematic biopsy, McNemar's test was used. The sensitivities of cancer detection for targeted biopsy, systematic biopsy and targeted combined systematic biopsy were compared using a $\chi^{2}$ test. The association between peak strain index and Gleason scores was compared with Spearman correlation analysis. To compare Gleason scores, the Wilcoxon rank sum test was performed. Values are presented as the mean \pm standard deviation. All statistical calculations were performed with SAS software version 9.3 (SAS Institute Inc., Cary, NC, USA). P<0.05 was considered to indicate a statistically significant difference.

\section{Results}

PSA and peak strain index value. A total of 141 patients were enrolled for prospective analysis. The average age was 71.6 years (range, 49-90), the mean PSA value was $30 \mathrm{ng} / \mathrm{ml}$ (range, 0.5-190) and the average prostate volume was $50.3 \mathrm{ml}$ (range, 15.8-178.5). According to the pathological results, $\mathrm{PCa}$ was detected in 51\% (72/141) patients. Patient characteristics, including age and PSA values, are summarized in Table I. The age and prostate volume in each group were similar, whereas the PSA values in the malignant group were significantly higher compared with the benign group $(\mathrm{P}<0.0001)$. The ranges of the peak strain index value in malignant and benign lesions of the prostate were 1.39-66.86 and 0.46-26.31 (mean, 24.79 and 3.02, respectively; $\mathrm{P}<0.0001$; Fig. 3).

Characterization of biopsy cores. In 141 patients, 159 suspicious are as detected by RTE were biopsied with 2 cores for each area. The positive incidence of PCa in RTE-targeted biopsy cores was 44\% (140/318 cores) and in systematic biopsy was $30.2 \%$ (426/1,410 cores). This indicated that the RTE targeted biopsy core had a significantly higher sensitively for detecting $\mathrm{PCa}(\mathrm{P}<0.0001)$.

The majority of the positive cores in RTE-targeted biopsy were identified in the apex and mid-gland (84\% of positive cores). Regarding the apex and mid-gland of the prostate, a higher frequency of positive PCa cores were detected in the right side of the prostate gland. However, using systematic biopsy, an increased number of positive PCa cores were identified in the middle and base of the gland. The distributions of PCa positive cores in the right or left side were similar in these approaches (Table II).

Detection of PCa inpatients using RTE-targeted biopsy and systematic biopsy. Among the 72 patients diagnosed with $\mathrm{PCa}$, 63 cases $(87.5 \%)$ were detected using RTE-targeted biopsy, 62 cases $(86.1 \%)$ using systematic biopsy and 53 cases $(74 \%)$ of PCa were detected by RTE-targeted and systematic biopsy. A total of 10 patients with PCa were detected using RTE-targeted biopsy alone and 9 patients using systematic biopsy alone. The sensitivity for cancer detection was $87.5 \%$ for RTE-targeted biopsy and $86.1 \%$ for systematic biopsy $(\mathrm{P}=0.525)$.

Optimal peak strain index value for the RTE-targeted biopsy. The higher peak strain index values demonstrated a higher sensitivity and specificity for predicting $\mathrm{PCa}$. When the peak strain index was $>5.97$ [AUC $=0.95$; $95 \%$ confidence interval (CI), 0.92-0.98], PCa was predicted with the highest sensitivity (87.5\%; 63/72 cases) and specificity (85.5\%; $53 / 69$ cases). When the PSA was $>10.1 \mathrm{ng} / \mathrm{ml}$ (AUC $=0.83$; 95\% CI, 0.76-0.89), the sensitivity and the specificity for detecting PCa were $80 \%$ and $72.2 \%$, respectively (Fig. 4).

RTE-targeted biopsy did not diagnose 9 patients with PCa that had a lower peak strain index value $(<5.97)$. The majority 
Table II. Number of PCa cores detected by RTE targeted biopsy and systematic biopsy.

\begin{tabular}{lccccccc}
\hline & \multicolumn{3}{c}{ RTE targeted biopsy } & & \multicolumn{3}{c}{ Systematic biopsy } \\
\cline { 2 - 3 } Core section & Right & Left & Overall (\%) & & Right & Left & Overall (\%) \\
\hline Apex & 38 & 20 & $58(41)$ & & 44 & 40 & $84(20)$ \\
Midgland & 38 & 22 & $60(43)$ & & 92 & 87 & $179(42)$ \\
Base & 10 & 12 & $22(16)$ & & 85 & 78 & $163(38)$ \\
Total & 86 & 54 & 140 & & 221 & 205 & 426 \\
\hline
\end{tabular}

PCa, prostate cancer; RTE, real-time tissue elastography.

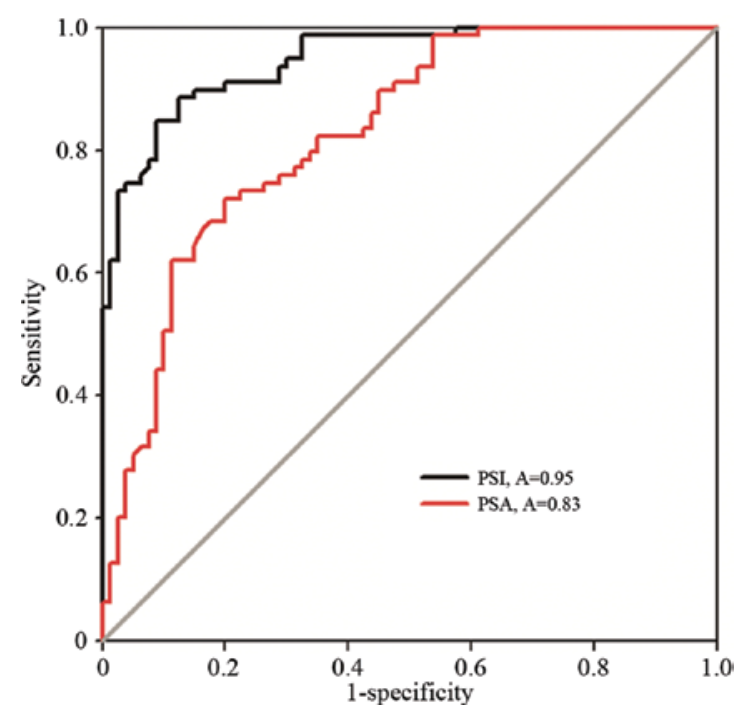

Figure 4. ROC curve analysis of the differentiation between benign and malignant prostate tissues. The data indicates that AUC values for the PSI were significantly higher compared with the PSA ( $\mathrm{P}=0.0003)$. The black line indicates the ROC curve for the PSI with an AUC of 0.95 (95\% CI, 0.92-0.98) The red line indicates the ROC curve for PSA with an AUC of 0.83 (95\% CI, 0.76-0.89). ROC, receiver operating characteristic; AUC, area under the curve; PSA, prostate specific antigen; PSI, peak strain index; A, area; CI, confidence interval.

of these 9 patients had multifocal and diffuse lesions in the prostate with a lower PSA value, lower Gleason score and were at an earlier clinical stage (Table III).

A total of 10 patients with a peak strain index of $\geq 5.97$ were diagnosed as having a benign prostate lesion. Of these 10 cases, 2 cases were benign prostate hyperplasia (BPH), 4 were $\mathrm{BPH}$ with chronic inflammation, 2 were granulomatous inflammation and 2 were low-grade prostate intraepithelial neoplasia.

According to the guidelines of the American Urological Association, the European Association of Urology and the Chinese Urological Association, cases of PCa were classified as low, moderate or high risk PCa (17-19) Moderate and high risk $\mathrm{PCa}$ (considered to be clinically important) must be treated as early as possible. Higher peak strain index values were associated with clinically significant $\mathrm{PCa}(\mathrm{r}=0.28 ; \mathrm{P}=0.017)$.

The Gleason scores of the 72 patients diagnosed with $\mathrm{PCa}$ were between 5 and 9 and the number that scored 5-6, 7 or 8-9 were 27, 25 and 20, respectively (Table IV). The overall positive incidence for RTE-targeted biopsy and systematic biopsy were 87.5 and $86.1 \%$, respectively $(\mathrm{P}=0.525)$. There was no significant difference in the distribution of Gleason scores between targeted biopsy and systematic biopsy $(\mathrm{P}=0.539)$. When the Gleason score was $\geq 7$, RTE targeted biopsy and systematic biopsy detected 95.6 (43/45) and 84.4\% (38/45) of PCa cases (Table IV), respectively, and the difference was statistically significant $(\mathrm{P}=0.0253)$. Therefore, an RTE-targeted biopsy coupled with a peak strain index of $\geq 5.97$ may be able to detect a higher number of clinically significant cases of $\mathrm{PCa}$ compared with systematic biopsy.

\section{Discussion}

PCa tissue is stiffer compared with normal prostate tissue (20). A number of previous studies, which applied the qualitative stiffness threshold 'blue area', indicated that RTE-guided biopsy was effective for detecting PCa $(4,10,21,22)$. Nygård et al (23) established that the frequency of positive cores was significantly higher in RTE-targeted biopsies compared with standard systematic biopsies. Another previous study indicated that additional patients that were not detected using 10-core biopsies were detected using RTE-targeted four-core biopsy (24). These previous studies suggest that the application of RTE-guided biopsy may be effective in prostate cancer detection and this is concordant with the current study that uses the objective quantitative parameter of stiffness in its approach.

Peak strain index is an objective quantitative parameter that reflects the stiffest region of the PCa tissue and has been established to be effective in distinguishing benign from malignant areas in the breast and thyroid gland $(25,26)$. A previous study demonstrated that the peak strain index in $\mathrm{PCa}$ lesions was higher compared with benign lesions with a threshold value of 17.4 (15). In the present study, the threshold value of the peak strain index was lower (5.97 vs. 17.4). The reasons for this variation may be that the methods used for calculating the peak strain index were varied. The size of the ROI was standardized as the smallest area compared with the SR results in other patients in the current study. It was important to select the appropriate site for the reference tissue and to measure $\mathrm{SR}_{\mathrm{B}}$ (peak strain index $=\mathrm{SR}_{\mathrm{B}} / \mathrm{SR}_{\mathrm{A}}$ ). Normal tissue is typically present as a green area on the elastogram $(27,28)$, therefore only the green area was selected, and not the blue or red merged areas, as the reference tissue to avoid any effect on ROI calculation. 
Table III. Number of patients in each peak strain group and PSA levels, Gleason score and clinical stage.

\begin{tabular}{|c|c|c|c|c|c|c|c|c|c|c|}
\hline & \multirow[b]{2}{*}{ Overall } & \multicolumn{3}{|c|}{$\mathrm{PSA}, \mathrm{ng} / \mathrm{ml}$} & \multicolumn{3}{|c|}{ Gleason score } & \multicolumn{3}{|c|}{ Clinical stage } \\
\hline & & $<10$ & $10-20$ & $>20$ & $\leq 6$ & 7 & $\geq 8$ & $\leq \mathrm{T}_{2 \mathrm{a}}$ & $\mathrm{T}_{2 \mathrm{~b}}$ & $\geq \mathrm{T}_{2 \mathrm{c}}$ \\
\hline Peak strain index $\geq 5.97$ & 63 & 11 & 16 & 36 & 20 & 24 & 19 & 8 & 8 & 47 \\
\hline Peak strain index $<5.97$ & 9 & 3 & 3 & 3 & 7 & 1 & 1 & 1 & 0 & 8 \\
\hline Total & 72 & 14 & 19 & 39 & 27 & 25 & 20 & 9 & 8 & 55 \\
\hline
\end{tabular}

PSA, prostate specific antigen.

Table IV. Number of patients with PCa and Gleason score distributions in the transrectal RTE targeted biopsy, systematic biopsy and combination groups.

\begin{tabular}{llll}
\hline Gleason score & TB & SB & TB+SB \\
\hline $5-6$ & 20 & 24 & 27 \\
7 & 24 & 21 & 25 \\
$8-9$ & 19 & 17 & 20 \\
Total & 63 & 62 & 72 \\
\hline
\end{tabular}

PCa, prostate cancer; TB, targeted biopsy; SB, systematic biopsy; RTE, real-time tissue electography.

The accuracy of systematic biopsy for detecting PCa varies depending upon the number of cores that are biopsied $(29,30)$. The sensitivity of the 12-core biopsy that adds additional lateral and apical peripheral zone biopsies is only 53\% (4). The 18 or 24 core 'saturation biopsy' does not increase the PCa detection rate (31). As the number of cores increase, the potential risk, including pain, bleeding and infection following biopsy, also increase $(32,33)$ RTE-targeted biopsy had a higher sensitivity with fewer biopsy cores compared with the systematic biopsy $(16,34)$.

In the present study, the rate of identifying patients with prostate cancer using RTE-targeted biopsy combined with peak strain index $(45 \%, 63 / 141$ cases) was similar compared with systematic biopsy $(44 \%, 62 / 141$ cases). RTE failed to detect 9 patients with PCa (6\%), of which7 cases $(78 \%)$ had a Gleason score $<7$ and 5 cases $(56 \%)$ had multifocal and diffuse lesions in the prostate gland. The possible hypotheses for the false-negative findings are that low risk PCa may be less stiff, or due to a lack of benign tissue for a reference. Notably, the majority of the false-positive findings were potentially associated with chronic inflammation or BPH with stromal hyperplasia and fibrosis. Junker et al (35) identified that the detection rate of PCa for RTE is dependent on tumor localization and histological type.

The distribution of Gleason scores between RTE-targeted biopsy and systematic biopsy were similar $(\mathrm{P}=0.539)$. However, when the peak strain index was $\geq 5.97$, RTE-targeted biopsy detected a higher number of clinically significant PCa cases compared with the systematic biopsy. This suggests that a positive peak strain index may be an independent marker for the detection of moderate and high-risk $\mathrm{PCa}$, which requires timely treatment.

Detection using RTE-targeted biopsy in varying parts of the prostate differs. Pelzer et al (36) indicated that RTE is effective in detecting apex and mid-gland PCa. This is possibly as the size and volume of the base area is too large for the probe to compress adequately. Secondly, the total detection rate of RTE-targeted biopsy on the right side was higher compared with that on the left (61 vs. 39\%). Salomon et al (37) theorized that this was due to the use of the left decubitus position during RTE. However, Pelzer et al (36) also demonstrated similar results with patients examined in the lithotomy position.

Magnetic resonance imaging (MRI) is an approach for targeted prostate biopsy. The three techniques of MRI guidance that are available $(38,39)$ are as follows: a) Cognitive targeting (physician performs a TRUS-guided biopsy following a review of the previous prostate MRI revealing a lesion); b) MRI/TRUS fusion (software co-registration of real-time TRUS with stored MRI); c) direct MRI-guided biopsy (in-bore targeting). In-bore targeting is a specific and direct targeting method, but its limitations include a long procedure time, high costs and position difficulties. By contrast, the advantages of RTE targeting combined with peak strain index are obvious. The advantages include: Less time required, cheaper and simpler for the patient to reach the left decubitus position.

The current study has a number of limitations. Firstly, the surrounding media stiffness region (green area) was selected as the reference tissue and chronic inflammatory, low-grade $\mathrm{PCa}$, multifocal and diffuse PCa lesions may also be displayed in green and, therefore, affect the peak strain index value. Secondly, there are artefacts in the elastogram that affect the calculation of the peak strain index, including lateral stiffness artefacts that typically occur in cases of BPH. The examination of the lateral suspicious region following the tilting of the ultrasound probe is effective to identify these artefacts. However, deep stiffness artefacts caused by the increasing depth of ultrasound penetration are challenging to overcome. This may reduce the ability to detect $\mathrm{PCa}$ in the transition zone and anterior-localized PCa in enlarged prostates (40). However, Miyagawa et al (41) demonstrated that a higher number of lesions in the anterior prostate were detected using elastography. Junker et al (42) indicated that between RTE and multiparametric MRI, there was no significant difference in the detection of anterior-localized PCa with a prostate volume of $<40 \mathrm{~cm}^{3}$. Thirdly, RTE has intra- and inter-observer variability as elastograms were produced by manual compression and the 
pressure and speed induced by manual compression maybe adjusted using a visual indicator. An experienced examiner (performed >500 examinations of patients) is required for performing reliable elastograms used for diagnosis of $\mathrm{PCa}$. Finally, the pathological diagnosis was based on biopsy cores.

To the best of our knowledge, the current study is the first to demonstrate that RTE-targeted biopsy combined with peak strain index may improve the detection rate of clinically significant PCa in the peripheral zone. The present study indicated that the peak strain index may be an effective quantitative parameter in RTE-targeted biopsy.

In conclusion, the results of the present study demonstrated that peak strain index as a quantitative parameter is an independent marker for $\mathrm{PCa}$ lesions in the prostate peripheral zone. Transrectal RTE-targeted biopsy combined with peak strain index may enhance the detection of clinically significant $\mathrm{PCa}$ with a small number of biopsy cores. RTE-targeted biopsy combined with systematic biopsy may provide an effective approach for the diagnosis of patients with PCa and, particularly, for those with clinically significant prostate cancer.

\section{Acknowledgements}

The present study was supported by the Suzhou Society Development Program (grant no. SYSD2014093) and the Superior Specialty Group Program of The Second Affiliated Hospital of Soochow University (grant no. XKQ2015009). The authors would like to thank Dr Jin Zhu, Dr Ya-Chen Zang (Department of Urology, The Second Affiliated Hospital of Soochow University, Suzhou, Jiangsu, P.R. China), Professor Yuan-Yuan Zhang (Wake Forest Institute for Regenerative Medicine, Wake Forest School of Medicine Center, Blvd, Winston-Salem, NC, USA) and Professor Zhou Wang (Department of Urology, University of Pittsburgh School of Medicine, Pittsburgh, PA, USA), for their assistance in manuscript preparation.

\section{References}

1. Jemal A, Bray F, Center MM, Ferlay J, Ward E and Forman D: Global cancer statistics. CA Cancer J Clin 61: 69-90, 2011.

2. Chen R, Ren SC; Chinese Prostate CancerConsortium, Yiu MK, Fai NC, Cheng WS, Ian LH, Naito S, Matsuda T, KehindeE, et al: Prostate cancer in Asia: A collaborative report. Asian J Urol 1: 15-29, 2014.

3. Shao Q, Ouyang J, Fan Y, Xie J, Zhou J, Wu J, Karim Kader A, $\mathrm{Xu}$ J, Liu G, Shan Y, et al: Prostate cancer in the senior men from rural areas in east district of China: Contemporary management and 5-year outcomes at multi-institutional collaboration. Cancer Lett 315: 170-177, 2012.

4. Haas GP, Delongchamps NB, Jones RF, Chandan V, Serio AM, Vickers AJ, Jumbelic M, Threatte G, Korets R, Lilja H and de la Roza G: Needle biopsies on autopsy prostates: Sensitivity of cancer detection based on true prevalence. J Natl Cancer Inst 99: 1484-1489, 2007.

5. Campos-Fernandes JL, Bastien L, Nicolaiew N, Robert G, Terry S, Vacherot F, Salomon L, Allory Y, Vordos D, Hoznek A, et al: Prostate cancer detection rate in patients with repeated extended 21-sample needle biopsy. Eur Urol 55: 600-606, 2009.

6. Schröder FH, Carter HB, Wolters T, van den Bergh RC, Gosselaar C, Bangma $\mathrm{CH}$ and Roobol MJ: Early detection of prostate cancer in 2007. Part 1: PSA and PSA kinetics. Eur Urol 53: 468-477, 2008.

7. Wolters T, Roobol MJ, van Leeuwen PJ, van den Bergh RC, Hoedemaeker RF, van Leenders GJ, Schröder FH and van der Kwast TH: A critical analysis of the tumor volume threshold for clinically insignificant prostate cancer using a data set of a randomized screening trial. J Urol 185: 121-125, 2011.
8. Phipps S, Yang TH, Habib FK, Reuben RL and McNeill SA: Measurement oftissue mechanical characteristics to distinguish between benign andmalignant prostatic disease. Urology 66 : 447-450, 2005.

9. Good DW, Stewart GD, Hammer S, Scanlan P, Shu W, Phipps S, Reuben R and McNeill AS: Elasticity as a biomarker for prostate cancer: A systematic review. BJU Int 113: 523-534, 2014.

10. Kapoor A, Kapoor A, Mahajan G and Sidhu BS: Real-time elastography in the detection of prostate cancer in patients with raised PSA level. Ultrasound Med Biol 37: 1374-1381, 2011.

11. Romagnoli A, Autieri G, Centrella D, Gastaldi C, Pedaci G, Rivolta L, Pozzi E, Anghileri A, Cerabino M, Bianchi CM and Roggia A: Real-time elastography in the diagnosis of prostate cancer: Personal experience. Urologia 77: 248-253, 2010 (In Italian).

12. Cochlin DL, Ganatra RH and Griffiths DF: Elastography in the detection of prostatic cancer. Clin Radiol 57: 1014-1020, 2002.

13. Ferrari FS, Scorzelli A, Megliola A, Drudi FM, Trovarelli S and Ponchietti R: Real-time elastography in the diagnosis of prostate tumor. J Ultrasound 12: 22-31, 2009.

14. Giurgiu CR, Manea C, Crişan N, Bungărdean C, Coman I and Dudea SM: Real-time sonoelastography in the diagnosis of prostate cancer. Med Ultrason 13: 5-9, 2011.

15. Zhang Y, Tang J, Li YM, Fei X, Lv FQ, He EH, Li QY and Shi HY: Differentiation of prostate cancer from benign lesions using strain index of transrectal real-time tissue elastography. Eur J Radiol 81: 857-862, 2012.

16. König K, Scheipers U, Pesavento A, Lorenz A, Ermert H and Senge T: Initial experiences with real-time elastography guided biopsies of the prostate. J Urol 174: 115-117, 2005.

17. Carter HB, Albertsen PC, Barry MJ, Etzioni R, Freedland SJ, Greene KL, Holmberg L, Kantoff P, Konety BR, Murad MH, et al: Early detection of prostate cancer: AUA guideline. J Urol 190: 419-426, 2013

18. Heidenreich A, Bastian PJ, Bellmunt J, Bolla M, Joniau S, van der Kwast T, Mason M, Matveev V, Wiegel T, Zattoni F, et al: EAU guidelines on prostate cancer. part 1: Screening, diagnosis, and local treatment with curative intent-update 2013. Eur Urol 65: 124-137, 2014.

19. Na YQ, Ye ZQ, Sun YH, Sun G, Huang J, Kong CZ, et al: Chinese guidelines for the diagnosis and treatment of Urologic diseases. 67-75, 2014 (monograph).

20. Krouskop TA, Wheeler TM, Kallel F, Garra BS and Hall T: Elastic moduli of breast and prostate tissues under compression. Ultrason Imaging 20: 260-274, 1998.

21. Scattoni V, Zlotta A, Montironi R, Schulman C, Rigatti P and Montorsi F: Extended and saturation prostatic biopsyin the diagnosis and characterisation of prostate cancer: A critical analysis of the literature. Eur Urol 52: 1309-1322, 2007.

22. Aigner F, Pallwein L, Schocke M, Andrei L, Junker D, Schäfer G, Mikuz G, Pedross F, Horninger W, Jaschke W, et al: Comparison of real-time sonoelastography with $\mathrm{T} 2$-weighted endorectal magnetic resonance imaging for prostate cancer detection. J Ultrasound Med 30: 643-649, 2011.

23. Nygård Y, Haukaas SA, Halvorsen OJ, Gravdal K, Frugård J, Akslen LA and Beisland C: A positive real-time elastography is an independent marker for detection of high-risk prostate cancers in the primary biopsy setting. BJU Int 113: E90-E97, 2014.

24. Salomon G, Drews N, Autier P, Beckmann A, Heinzer H, Hansen J, Michl U, Schlomm T, Haese A, Steuber T, et al: Incremental detection rate of prostate cancer by real-time elastography targeted biopsies in combination with a conventional 10 -core biopsy in 1024 consecutive patients. BJU Int 113: 548-553, 2014.

25. Cho N, Moon WK, Kim HY, Chang JM, Park SH and Lyou CY: Sonoelastographic strain index for differentiation of benign and malignant nonpalpable breast masses. J Ultrasound Med 29: 1-7, 2010.

26. Lyshchik A, Higashi T, Asato R, Tanaka S, Ito J, Mai JJ, Pellot-Barakat C, Insana MF, Brill AB, Saga T, et al: Thyroid gland tumor diagnosis at US elastography. Radiology 237: 202-211, 2005

27. Kamoi K, Okihara K, Ochiai A, Ukimura O, Mizutani Y, Kawauchi A and Miki T: The utility of transrectal real-time elastography in the diagnosis of prostate cancer. Ultrasound Med Biol 34: 1025-1032, 2008.

28. Goddi A, Sacchi A, Magistretti G and Almolla J: Transrectal real-time elastography of the prostate: Normal patterns. J Ultrasound 14: 220-232, 2011.

29. Chen ME, Troncoso P, Johnston DA, Tang K and Babaian RJ: Optimization of prostate biopsy strategy using computer based analysis. J Urol 158: 2168-2175, 1997. 
30. Norberg M, Egevad L, Holmberg L, Sparen P, Norlén BJ and Busch C: The sextant protocol for ultrasound-guided core biopsies of the prostate underestimates the presence of cancer. Urology 50: 562-566, 1997.

31. Jones JS, Patel A, Schoenfield L, Rabets JC, Zippe CD and Magi-Galluzzi C: Saturation technique does not improve cancer detection as an initial prostate biopsy strategy. J Urol 175: 485-488, 2006

32. Jones JS, Patel A, Schoenfield L, Rabets JC, Zippe CD and Magi-Galluzzi C: Saturation technique does not improve cancer detection as an initial prostate biopsy strategy. J Urol 175: 485-488, 2006

33. Naughton CK, Miller DC, Mager DE, Ornstein DK and Catalona WJ: A prospective randomized trial comparing 6 versus 12 prostate biopsy cores: Impact on cancer detection. J Urol 164: 388-392, 2000

34. Pallwein L, Mitterberger M, Struve P, Horninger W, Aigner F, Bartsch G, Gradl J, Schurich M, Pedross F and Frauscher F: Comparison of sonoelastography guided biopsy with systematic biopsy: Impact on prostate cancer detection. Eur Radiol 17: 2278-2285, 2007.

35. Junker D, Schäfer G, Aigner F, Schullian P, Pallwein-Prettner L, Bektic J, Horninger W, Halpern EJ and Frauscher F: Potentials and limitations of real-time elastography for prostate cancer detection: A whole-mount step section analysis. Scientific World Journal 2012: 193213, 2012.

36. Pelzer AE, Heinzelbecker J, Weiß C, Frühbauer D, Weidner AM, Kirchner M, Stroebel P, Schoenberg SO and Dinter DJ: Real-time sonoelastography compared to magnetic resonance imaging using four different modalities at 3.0 T in the detection of prostate cancer: Strength and weaknesses. Eur J Radiol 82: 814-821, 2013.
37. Salomon G, Köllerman J, Thederan I, Chun FK, Budäus L, Schlomm T, Isbarn $\mathrm{H}$, Heinzer $\mathrm{H}$, Huland $\mathrm{H}$ and Graefen $\mathrm{M}$ : Evaluation of prostate cancer detection with ultrasound real-time elastography: A comparison with step section pathological analysis after radical prostatectomy. Eur Urol 54: 1354-1362, 2008.

38. Kim CK: Magnetic resonance imaging-guided prostate biopsy: Present and future. Korean J Radiol 16: 90-98, 2015

39. Tilak G, Tuncali K, Song SE, Tokuda J, Olubiyi O, Fennessy F, Fedorov A, Penzkofer T, Tempany C and Hata N: 3T MR-guided in-bore transperineal prostate biopsy: A comparison of robotic and manual needle-guidance templates. J Magn Reson Imaging 42: 63-71, 2015.

40. Junker D, De Zordo T, Quentin M, Ladurner M, Bektic J, Horniger W, Jaschke W and Aigner F: Real-time elastography of the prostate. Bio Med Res Int 2014: 180804, 2014.

41. Miyagawa T, Tsutsumi M, Matsumura T, Kawazoe N, Ishikawa S, Shimokama T, Miyanaga N and Akaza H: Real-time elastography for the diagnosis of prostate cancer: Evaluation of elastographic moving images. Jpn J Clin Oncol 39: 394-398, 2009.

42. Junker D, Schäfer G, Kobel C, Kremser C, Bektic J, Jaschke W and Aigner F: Comparison of real-time elastography and multiparametric MRI for prostate cancer detection: A whole-mount step-section analysis. AJR Am J Roentgenol 202: W263-W269, 2014. 